Удк 676.16

\title{
ХАРАКТЕРИСТИКА ГЕОМЕТРИЧЕСКИХ ПАРАМЕТРОВ ВОЛОКОН ЦЕЛЛЮЛОЗНЫХ ПОЛУФАБРИКАТОВ С ИСПОЛЬЗОВАНИЕМ ВЕРОЯТНОСТНЫХ МЕТОДОВ
}

\section{(C) Я.В. Казаков}

\author{
Северный (Арктический) федеральный университет им. М.В. Ломоносова, \\ наб. Северной Двины, 17, Архангельск, 163002 (Россия), \\ e-mail: j.kazakov@narfu.ru
}

Представлены результаты расчета параметров распределения основных характеристик хвойных и лиственных целлюлозных волокон, измеренных на автоматическом анализаторе волокна FiberTester - длины, ширины, фактора формы. Предложено использовать параметры распределения характеристик отдельных волокон для количественной оценки бумагообразующего потенциала волокнистых полуфабрикатов и моделирования структуры бумаги с адекватной вероятностно-статистической характеристикой по волокну.

Ключевые слова: волокно, сульфатная целлюлоза, геометрические размеры волокна, параметры распределения.

\section{Введение}

Для массового производства бумаги и картона используется волокно растительного происхождения, получаемое главным образом из древесины. Основным сырьем для производства волокна в России служит древесина хвойных (сосна, ель) и лиственных (береза, осина) пород, которые широко распространены в Российской Федерации.

Для прогнозирования качества бумаги и картона требуются знания о структурно-морфологических свойствах волокнистых полуфабрикатов, которые в значительной мере определяют их бумагообразующие свойства [1]. Для их контроля и углубленного исследования требуется применение новейших инструментальных методов. Традиционно при анализе качества полуфабрикатов в бумажной промышленности из целого ряда характеристик выделяют как важнейшие среднюю длину и ширину волокон, а также фракционный состав по длине волокна. Данная количественная информация о стохастической волокнистой композиции позволяет прогнозировать её влияние на механические свойства бумаги и картона [2]. Математическое описание геометрических характеристик волокон в бумажной массе в сильной степени осложняется тем, что волокна различны по размерам, форме, морфологии и степени разработки при размоле [2, 3]. Поэтому для описания стохастической волокнистой массы логично использование вероятностно-статистических методов. При этом параметры распределения характеристик отдельных волокон играют роль переменных, оценивающих бумагообразующий потенциал композиции бумажной массы. Наличие математической базы количественного описания геометрии волокон в бумажной массе открывает возможность моделирования структуры бумаги с адекватной вероятностно-статистической характеристикой по волокну.

Применяемые сегодня современные анализаторы волокна позволяют в автоматическом режиме провести измерения характеристик отдельных волокон при пропускании суспензии волокон через измерительную ячейку и получить гистограммы распределения длины и ширины волокон, а также характеристик, оценивающих кривизну волокон [4], числа изломов на волокне и т.п. Во всех случаях результаты пред-

Казаков Яков Владимирович - заведующий кафедрой технологии целлюлозно-бумажного производства, кандидат технических наук, доцент, тел.: (8182) 65-74-82, e-mail: j.kazakov@narfu.ru ставляются в виде среднего значения, гистограммы распределения характеристик и нескольких величин размеров волокон, учитывающих взвешенную, объемную или массовую долю. Однако практическое 
использование гистограммы распределения как характеристики волокна, затруднено, поскольку она представляет собой массив данных. При этом сокращение числа классов в гистограмме, уменьшающее размер выходного массива результатов, приводит к снижению чувствительности к различиям размеров волокон разной степени обработки в классах. Установление вида и оценка параметров распределения длины, ширины и формы отдельных волокон позволяет перейти от массивов данных к всего двум характеристикам параметрам распределения.

\section{Экспериментальная часть}

Исходными данными для определения параметров распределения приняты результаты измерения на анализаторе волокна L\&W FiberTester [4], установленного и функционирующего в лаборатории кафедры технологии ЦБП САФУ. Примеры наиболее часто используемых в практике характеристик волокна хвойной и лиственной сульфатной целлюлозы, получаемых при измерении и обработке результатов измерений, выполняемых программой FiberTester, представлены в таблице 1.

Программное обеспечение анализатора FiberTester позволяет, кроме выполнения всевозможных и разнообразных расчетов, выполнить экспорт исходных данных длины $l$, мм, ширины, $w$, мкм, и фактора формы $f$, процент каждого волокна. Полученная выборка из характеристик объемом до 20 тысяч волокон обработана нами с использованием специально разработанного программного обеспечения [5] (рис. 1). Данная программа позволяет произвольно и быстро задавать количество и размер классов, настраивать параметры учета мелочи и фильтра «мусора», причем, в отличие от программы FiberTester, делать это после проведения измерений.

Проведенная ранее проверка статистической гипотезы о принадлежности выборки данных к тому или иному распределению по критерию $\chi^{2}$ (Пирсона) показала, что экспериментальные данные для длины и ширины волокна не противоречат гипотезе о принадлежности выборки к логарифмически нормальному распределению с параметрами $\mu$ и $\sigma_{x}$, а данные для кривизны волокна - экспоненциальному распределению с параметром $\lambda[6]$.

При выполнении дополнительной статистической обработки были построены гистограммы и вычислены параметры распределения для длины, ширины, и фактора формы. В связи со специфичным видом гистограммы распределения фактора формы $f$ вместо него использовали фактор кривизны волокна $(K r)$, который определяется как $(100-f) / 100$. Результаты вычисления параметров распределения длины, ширины и кривизны волокон для проанализированных образцов целлюлозы представлены в таблице 2.

Параметры распределения характеристик волокон были вычислены не только для всей выборки волокон, но и для каждого класса волокон по длине. Результаты представлены в таблице 3. Примеры гистограмм распределения ширины и фактора формы для всех измеренных волокон и отдельных классов по длине представлены на рисунке 2 , на рисунке 3 - графики зависимости длины $(l$, мм) и ширины $(w$, мкм) волокон, а также длины и фактора формы $(f, \%)$ для всех волокон, средних значений в классах и отдельных классов по длине.

Таблица 1. Наиболее часто используемые в практике результаты измерений и расчетов, выполняемых программой анализатора волокна FiberTester

\begin{tabular}{|c|c|c|c|c|c|}
\hline \multirow{2}{*}{$\begin{array}{c}\text { Вид сульфатной цел- } \\
\text { люлозы }\end{array}$} & \multicolumn{3}{|c|}{ Средняя длина волокна, мм } & \multirow{2}{*}{$\begin{array}{c}\text { Средняя ши- } \\
\text { рина, мкм }\end{array}$} & \multirow{2}{*}{$\begin{array}{l}\text { Средний фак- } \\
\text { тор формы, \% }\end{array}$} \\
\hline & арифметическая & $\begin{array}{c}\text { взвешенная } \\
\text { по длине }\end{array}$ & $\begin{array}{c}\text { взвешенная } \\
\text { по массе }\end{array}$ & & \\
\hline Лиственная небеленая & 0,823 & 0,973 & 1,096 & 21,2 & 91,9 \\
\hline Лиственная беленая & 0,773 & 0,926 & 1,058 & 20,4 & 91,8 \\
\hline Хвойная небеленая & 1,729 & 2,579 & 3,094 & 28,2 & 88,7 \\
\hline Хвойная беленая & 1,143 & 1,874 & 2,538 & 22,7 & 88,8 \\
\hline
\end{tabular}

Таблица 2. Параметры распределения для длины, ширины и кривизны волокна

\begin{tabular}{|c|c|c|c|c|c|}
\hline \multirow{4}{*}{$\begin{array}{c}\text { Вид сульфатной цел- } \\
\text { люлозы }\end{array}$} & \multicolumn{5}{|c|}{ Параметры распределения волокон } \\
\hline & \multicolumn{2}{|c|}{ Длина } & \multicolumn{2}{|c|}{ Ширина } & \multirow{3}{*}{$\begin{array}{c}\text { Кривизна } \\
\text { Экспоненцильное } \\
\lambda\end{array}$} \\
\hline & \multicolumn{4}{|c|}{ Логарифмически нормальное } & \\
\hline & $\mu$ & $\sigma_{x}$ & $\mu$ & $\sigma_{x}$ & \\
\hline Лиственная небеленая & $-0,294$ & 0,482 & 3,035 & 0,201 & 12,33 \\
\hline Лиственная беленая & $-0,362$ & 0,484 & 2,987 & 0,234 & 11,18 \\
\hline Хвойная небеленая & 0,262 & 0,822 & 3,301 & 0,277 & 8,85 \\
\hline Хвойная беленая & $-0,130$ & 0,774 & 3,084 & 0,777 & 8,96 \\
\hline
\end{tabular}



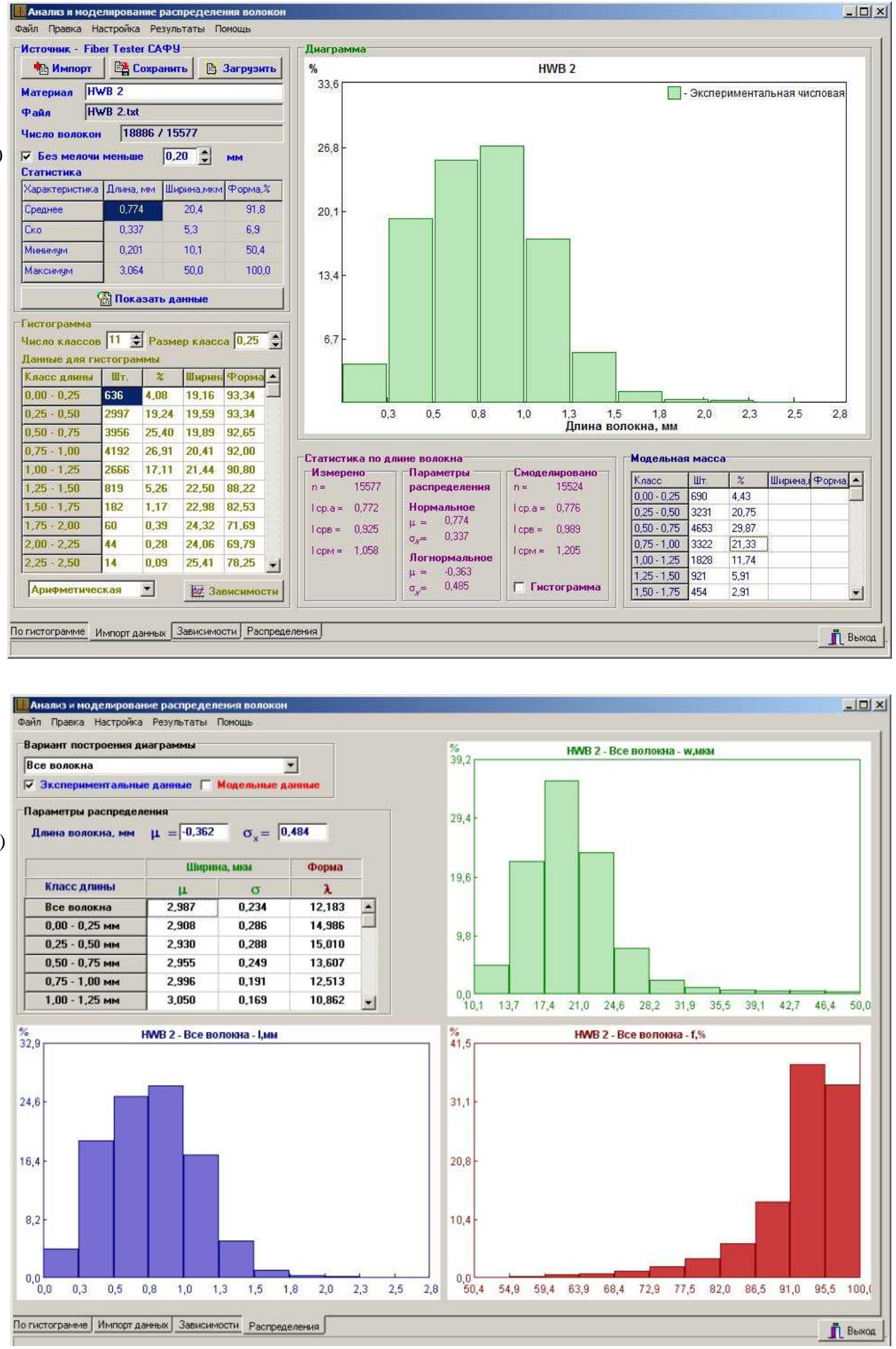

Рис. 1. Вид экрана при работе программы по расчету параметров распределения характеристик волокон [5]: $a$ - на этапе расчета общих характеристик; $\sigma$ - на этапе расчета параметров распределения в классах длины волокна 
a)

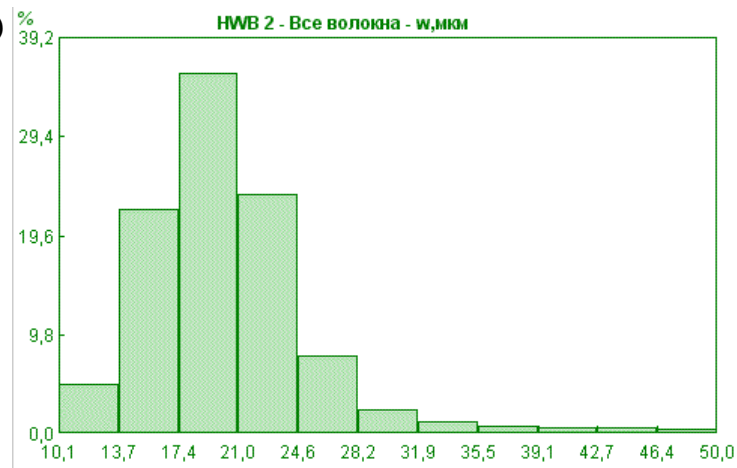

B)

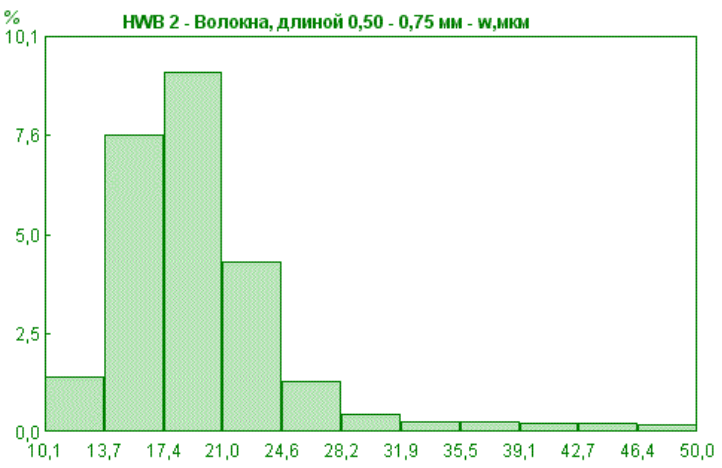

д)

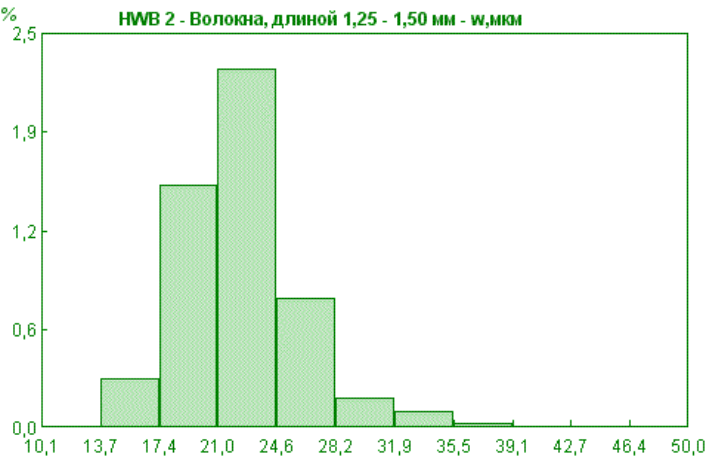

б)

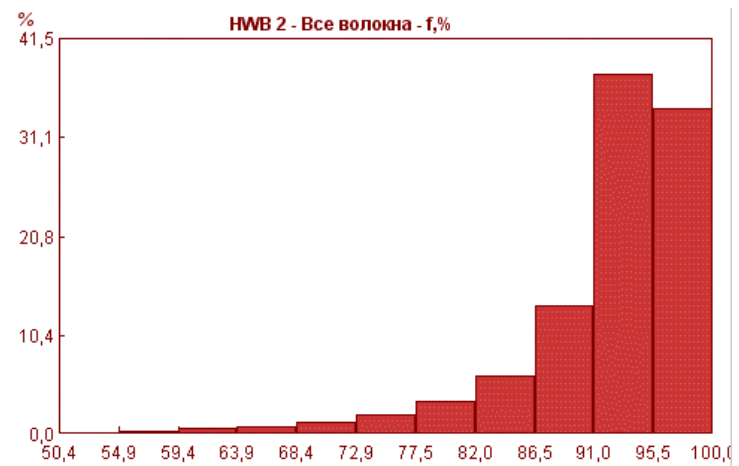

г)



e) $\%$

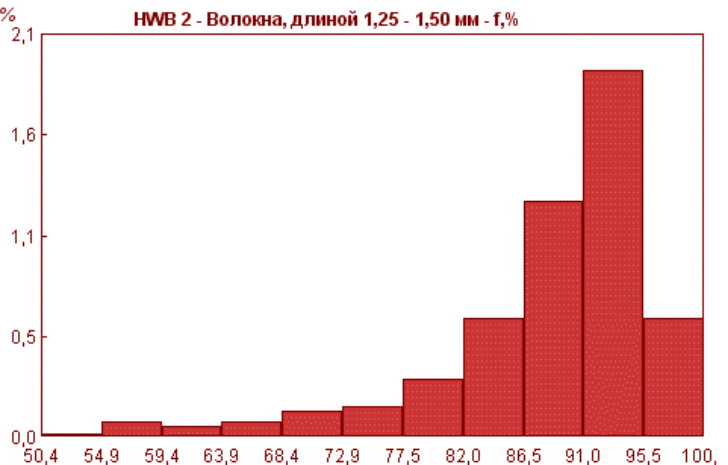

Рис. 2. Гистограммы распределения ширины $(a, 6, \partial)$ и фактора формы $(\sigma, 2, e)$ волокон лиственной сульфатной беленой целлюлозы: $a, \sigma$ - все волокна; 8,2 - волокна класса длиной 0,5-0,75 мм; $\partial, e$ - волокна класса длиной 0,25-1,50 мм (начало)

Таблица 3. Параметры распределения ширины $\left(\mu, \sigma_{x}\right)$ и кривизны $(\lambda)$ волокон для отдельных классов по длине

\begin{tabular}{|c|c|c|c|c|c|c|}
\hline \multirow{2}{*}{$\begin{array}{c}\text { Классы по } \\
\text { длине волокна, мм }\end{array}$} & \multicolumn{3}{|c|}{ Небеленая целлюлоза } & \multicolumn{3}{|c|}{ Беленая целлюлоза } \\
\hline & $\mu$ & $\sigma_{x}$ & $\lambda$ & $\mu$ & $\sigma_{x}$ & $\lambda$ \\
\hline 1 & 2 & 3 & 4 & 5 & 6 & 7 \\
\hline \multicolumn{7}{|c|}{ Лиственная целлюлоза } \\
\hline $0,00-0,25$ & 2,969 & 0,263 & 14,598 & 2,908 & 0,286 & 14,986 \\
\hline $0,25-0,50$ & 2,980 & 0,260 & 14,553 & 2,930 & 0,288 & 15,010 \\
\hline $0,50-0,75$ & 2,999 & 0,220 & 14,239 & 2,955 & 0,249 & 13,607 \\
\hline $0,75-1,00$ & 3,037 & 0,171 & 13,125 & 2,996 & 0,191 & 12,513 \\
\hline $1,00-1,25$ & 3,077 & 0,140 & 11,495 & 3,050 & 0,169 & 10,862 \\
\hline $1,25-1,50$ & 3,120 & 0,135 & 9,174 & 3,099 & 0,166 & 8,480 \\
\hline $1,50-1,75$ & 3,154 & 0,142 & 6,920 & 3,118 & 0,178 & 5,695 \\
\hline $1,75-2,00$ & 3,147 & 0,172 & 4,029 & 3,178 & 0,219 & 3,501 \\
\hline $2,00-2,25$ & 3,178 & 0,194 & 3,332 & 3,162 & 0,188 & 3,310 \\
\hline $2,25-2,50$ & 3,179 & 0,192 & 3,600 & 3,205 & 0,184 & 4,634 \\
\hline
\end{tabular}


Окончание таблицьь 3

\begin{tabular}{c|c|c|c|c|c|c|c}
\hline & 2 & 3 & 4 & 5 & 6 & 7 \\
\hline \multicolumn{7}{l|}{} & \multicolumn{1}{c|}{ Хвойная целлюлоза } \\
$0,00-0,50$ & 3,153 & 0,326 & 11,415 & 2,994 & 0,316 & 12,702 \\
$0,50-1,00$ & 3,237 & 0,290 & 10,785 & 3,011 & 0,248 & 10,329 \\
$1,00-1,50$ & 3,285 & 0,260 & 9,831 & 3,090 & 0,213 & 8,131 \\
$1,50-2,00$ & 3,336 & 0,244 & 8,672 & 3,225 & 0,214 & 6,634 \\
$2,00-2,50$ & 3,357 & 0,230 & 8,176 & 3,260 & 0,192 & 6,148 \\
$2,50-3,00$ & 3,392 & 0,215 & 7,583 & 3,290 & 0,187 & 6,006 \\
$3,00-3,50$ & 3,400 & 0,205 & 7,055 & 3,321 & 0,190 & 5,903 \\
$3,50-4,00$ & 3,432 & 0,208 & 6,876 & 3,338 & 0,185 & 5,785 \\
$4,00-4,50$ & 3,441 & 0,214 & 6,081 & 3,340 & 0,188 & 5,664 \\
$4,50-5,00$ & 3,432 & 0,175 & 6,065 & 3,376 & 0,113 & 4,856 \\
$5,00-5,50$ & 3,423 & 0,173 & 4,477 & 3,348 & 0,205 & 5,469 \\
$5,50-6,00$ & 3,561 & 0,179 & 3,380 & 3,533 & 0,048 & 4,057 \\
\hline
\end{tabular}

a)

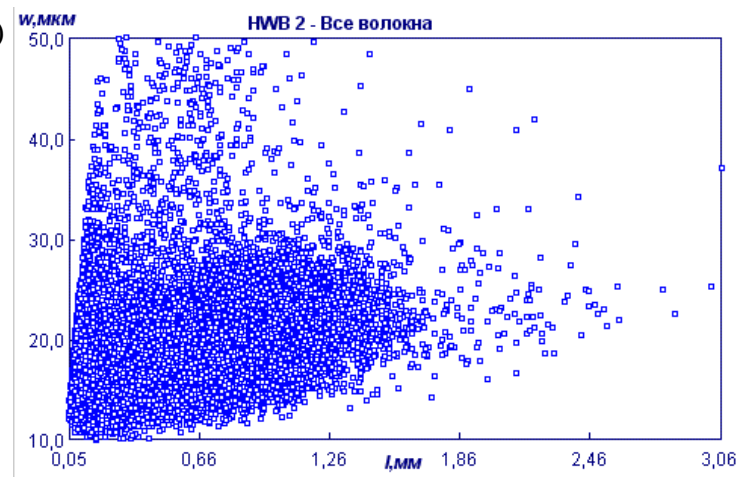

B)

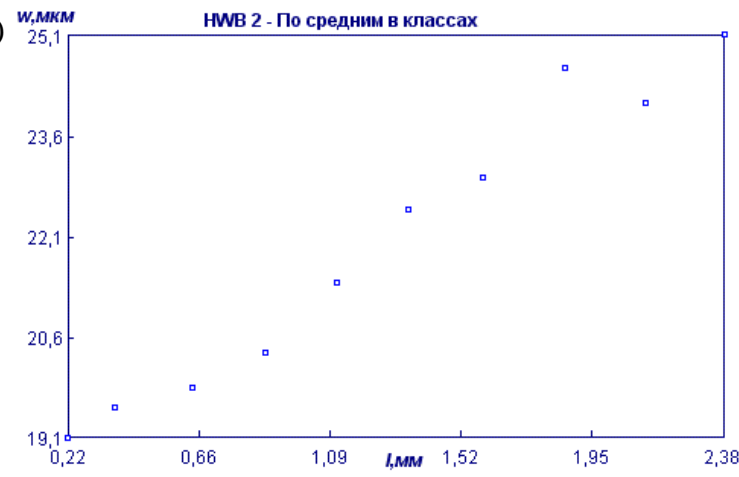

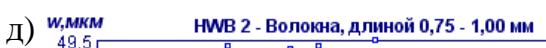

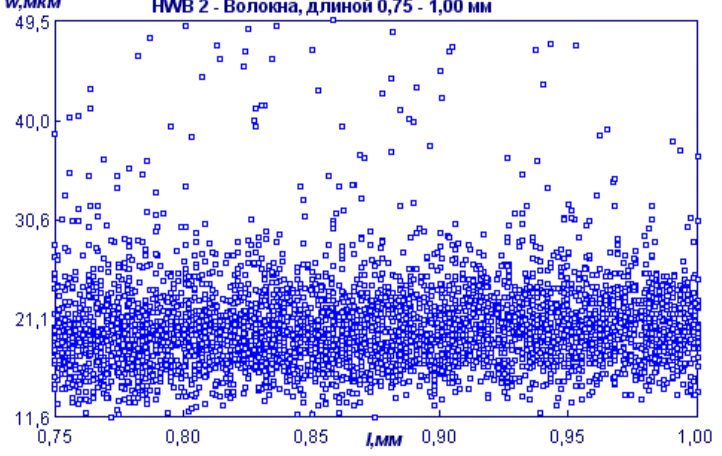

б) $1, \%$

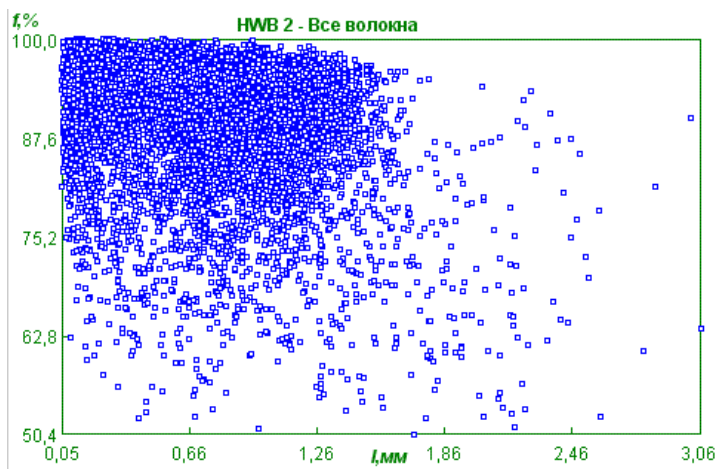

г)



e) 5,0

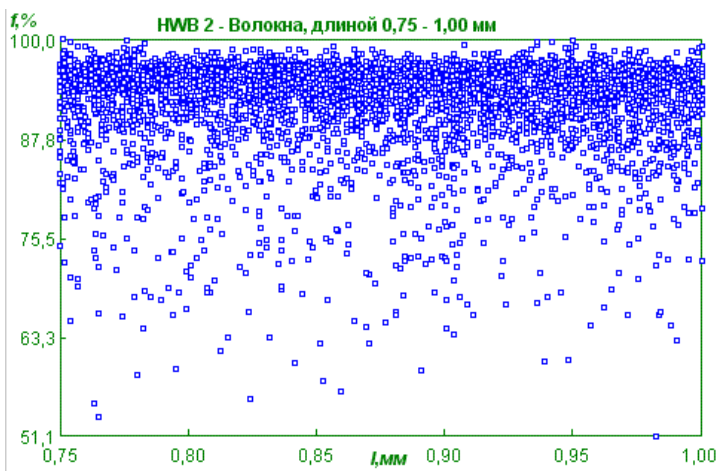

Рис. 3. Зависимости между длиной $l$ и шириной $w$ волокон $(a, b, \partial)$ и между длиной $l$ и фактором формы $f$ волокон $(\sigma, 2, e)$ для всех волокон $(a, \sigma)$; по средним значениям в классах длины $(в, 2)$; для волокон с длиной 0,75-1,0 мм для сульфатной лиственной беленой целлюлозы 


\section{Обсуждение результатов}

Данные, представленные в таблицах 2 и 3, свидетельствуют, что имеет место различие величин параметров распределения всех волокон и волокон в определенном классе длины, а также указывают на существование зависимости параметров распределения ширины и кривизны волокон в каждой фракции от размера класса. Это подтверждено для лиственной и хвойной целлюлозы. Изменение средней длины и ширины волокна и фактора формы $f$ (табл. 1) в зависимости от вида целлюлозы, соответствует изменению параметров $\mu$ и $\lambda$ (табл. 2). Более высокая полидисперсность волокон хвойной целлюлозы приводит к большим значениям параметров распределения $\sigma_{x}$, характеризующих разброс значений.

Таким образом, параметры распределения характеристик отдельных волокон можно использовать для количественной оценки бумагообразующего потенциала волокнистой массы.

Изменение значений параметров распределения ширины и кривизны волокна в зависимости от длины волокон в классе свидетельствует, что должна существовать зависимость между длиной, шириной и кривизной волокон.

Дополнительная математическая обработка данных раскрывает возможности по анализу взаимосвязи характеристик отдельных волокон. На рисунке 3 представлены графики зависимости длины $(l$, мм) и ширины ( $w$, мкм) волокон, а также длины и фактора формы $(f, \%)$. Результаты для всей выборки волокон (рис. $3, a, \sigma)$ не позволяют утверждать о существовании четко выраженной связи между длиной и шириной волокон, длиной и формой, шириной и формой. Результаты для средних значений в классах длины (рис. 3, 8, 2), наоборот, свидетельствуют о четкой зависимости между длиной, шириной и формой волокон - более длинные волокна в среднем являются более широкими и менее прямыми. В то же время, если рассматривать волокна в отдельном классе длины (рис. $3, \partial, e$ ), то такая связь отсутствует вообще. Поэтому для описания стохастической волокнистой массы логично использование вероятностно-статистических методов.

\section{Bblводbl}

1. Доказана возможность математического описания геометрии волокон полидисперсного целлюлозного полуфабриката с использованием вероятностно-статистических методов. Рассчитаны параметры логарифмически нормального распределения для длины и ширины волокон и экспоненциального для кривизны волокон.

2. Изменение средних значений длины и ширины волокна и фактора формы в зависимости от вида целлюлозы, соответствует изменению параметров распределения $\mu$ и $\lambda$.

3. Экспериментально подтверждено, что взаимосвязь между отдельными характеристиками целлюлозных волокон имеет вероятностный характер, поскольку строгие функциональные зависимости имеют место только для средних значений в классах длины, а внутри отдельного класса по длине такие связи отсутствуют полностью.

4. На основании экспериментальных исследований подготовлена математическая база для количественного описания состояния волокон в бумажной массе с применением вероятностно-статистических методов. Это дает возможность в дальнейшем провести работу по разработке компьютерной модели бумажного листа с учетом полидисперсности волокон по длине, ширине и кривизны волокон.

\section{Список литературь}

1. Фляте Д.М. Свойства бумаги. СПб., 1999. 384 с.

2. Кларк Дж. Технология целлюлозы (Наука о целлюлозной массе и бумаге, подготовка массы, переработка её в бумагу, методы испытаний). М., 1983. 456 с.

3. Niskanen K., Kajanto I., Pakariner P. Papermaking Science and Technology. Paper physics. Otaniemi, 2008. Vol. 16. $324 \mathrm{p}$.

4. Karlsson H. Fiber Guide. Fiber analysis and process applications in the pulp and paper industry. AB Lorentzen\&Werrte. 2006. 120 p.

5. Свид. №2012612982 (РФ). Свидетельство о государственной регистрации программы для ЭВМ. Программа для анализа и моделирования распределения по длине и ширине целлюлозных волокон в бумажной массе (Моделирование фракционного состава) / Я.В. Казаков. / 26.03.2012.

6. Зеленова С.В. Влияние структуры целлюлозно-бумажных материалов на их деформационные и прочностные свойства : дис. ... канд. техн. наук. Архангельск, 2007. 152 с. 
Kazakov $Y$. THE CHARACTERISTIC OF GEOMETRICAL PARAMETERS OF CELLULOSE FIBERS IN PULP USING PROBABILISTIC APPROACH

Northern (Arctic) Federal University named after M.V. Lomonosov, Severnaya Dvina Emb. 17, Arkhangelsk, 163002 (Russia),e-mail: j.kazakov@narfu.ru

Advantages of the mathematical description of geometrical fibers parameters of the polydisperse cellulose half-finished product measured on the automatic analyzer FiberTester using probabilistic-statistical methods are shown. With application specially developed and registered in Federal Institute Industrial Property software the possibilities of additional processing of experimental data are shown. Parameters of lognormal distribution for length and width of fibers with parameters $\mu$ and $\sigma_{x}$, and exponential distribution for curvature of fibers with parameter $\lambda$ for hardwood and softwood kraft pulp, both bleached and not bleached are calculated.

It is established, that changes of average values of fiber length and width and the form-factor, corresponds to change of parameters of distribution $\mu$ and $\lambda$ for different grades of kraft pulp

It is experimentally confirmed, that the interrelation between separate characteristics of cellulose fibers has probabilistic character as strict functional dependences take place only for average values in classes of length, and in a separate class on length such dependences are absent completely.

It is offered to use distribution parameters of fibers characteristics for a quantitative estimation papermaking potential of fibrous half-finished products and modeling of paper structure with the adequate fiber probabilistic-statistical characteristic.

Keywords: fibers, kraft pulp, fiber geometrical sizes, distribution parameters.

\section{References}

1. Fliate D.M. Svoistva bumagi. [Properties of the paper.]. St. Petersburg, 1999, 384 p. (in Russ.).

2. Klark Dzh. Tekhnologiia tselliulozy (Nauka o tselliuloznoi masse i bumage, podgotovka massy, pererabotka ee $v$ bumagu, metody ispytanii). [Cellulose Technology (Science of pulp and paper, weight training, processing it in the paper, test methods).]. Moscow, 1983, 456 p. (in Russ.).

3. Niskanen K., Kajanto I., Pakariner P. Papermaking Science and Technology. Paper physics. Otaniemi, 2008. Vol. 16. $324 \mathrm{p}$.

4. Karlsson H. Fiber Guide. Fiber analysis and process applications in the pulp and paper industry. AB Lorentzen\&Werrte. 2006. 120 p.

5. №2012612982 (RU). Svidetel'stvo o gosudarstvennoi registratsii programmy dlia EVM. Programma dlia analiza $i$ modelirovaniia raspredeleniia po dline $i$ shirine tselliuloznykh volokon $v$ bumazhnoi masse (Modelirovanie fraktsionnogo sostava). [Certificate of state registration of the computer. Program for the analysis and modeling of the distribution of the length and width of the cellulose fibers in the paper pulp (Modeling fractional composition]. Ia.V. Kazakov. 26.03.2012. (in Russ.).

6. Zelenova S.V. Vliianie struktury tselliulozno-bumazhnykh materialov na ikh deformatsionnye $i$ prochnostnye svoistva: dis. ... kand. tekhn. nauk. [Influence of the structure of pulp and paper materials on their deformation and strength properties: Candidate of Technical Sciences dissertation]. Arkhangelsk, 2007, 152 p. (in Russ.).

Received March 23, 2013 
